\title{
Educação e desenvolvimento: inflexões na política educacional amapaense (1944-2002)
}

Sidney Lobato'

RESUMO

Este artigo analisa e compara duas políticas educacionais realizadas no Amapá. A primeira fora levada a cabo pelo governo de Janary Gentil Nunes (1944-1956) e tinha por meta formar trabalhadores disciplinados e aptos a colaborar na geração de grandes excedentes comercializáveis, por meio da exaustiva exploração de recursos naturais locais. A segunda fora efetivada pelo governo de João Alberto Capiberibe (1995-2002) e visava à disseminação de uma consciência ambiental que levasse os amapaenses a valorizar tanto a preservação do meio ambiente quanto as formas tradicionais de vida e trabalho. A comparação entre essas políticas evidenciou que a educação, nos dois períodos, foi percebida como um fundamental instrumento de transformação das práticas sociais, tendo em vista a melhoria da qualidade de vida dos cidadãos. Ficou também evidente que os dois governos tinham visões muito díspares de desenvolvimento regional e, portanto, dos valores a serem difundidos por meio das escolas.

\section{PALAVRAS-CHAVE}

política educacional; desenvolvimento; Amapá.

'Universidade Federal do Amapá, Macapá, AP, Brasil. 


\title{
EDUCATION AND DEVELOPMENT: TRANSFORMATIONS IN THE AMAPAENSE EDUCATIONAL POLICY (1944-2002)
}

\begin{abstract}
This article analyzes and compares two educational policies carried out in Amapá State. The first one was carried out by the Janary Gentil Nunes's government (1944-1956) and aimed to train disciplined workers able to collaborate in the generation of large marketable surpluses through the exhaustive exploitation of local natural resources. The second was carried out by the João Alberto Capiberibe's government (1995-2002) and aimed at the dissemination of an environmental awareness that would lead the amapaenses to value both the environmental preservation and the traditional ways of life and work. The comparison between these policies showed that the education in both periods was noticed as a fundamental instrument for transforming social practices, on the point of view to improve the life quality of citizens. It has been also evident that the two governments concerned have had very different visions about regional development and, therefore, about the values to be diffused through the schools.
\end{abstract}

KEYWORDS

educational policy; development; Amapá.

\section{EDUCACIÓN Y DESARROLLO: INFLEXIONES EN LA POLÍTICA EDUCATIVA AMAPAENSE (1944-2002)}

\section{RESUMEN}

En este artículo se analiza y compara dos políticas educativas implementadas en Amapá. La primera había sido llevada a cabo por el gobierno de Janary Gentil Nunes (1944-1956) y tenía la meta de obtener trabajadores capaces de colaborar en la generación de grandes excedentes comercializables a través de la exhaustiva explotación de los recursos naturales locales. La segunda fue llevada a cabo por el gobierno de João Alberto Capibaribe (1995-2002) y fue dirigido a la difusión de la conciencia ambiental a tomar el Amapá tanto como a valorar la preservación del medio ambiente y las formas tradicionales de vida y de trabajo. La comparación entre estas políticas mostró que la educación, en ambos períodos, se percibe como un instrumento clave de la transformación de las prácticas sociales, con el fin de mejorar la calidad de vida de los ciudadanos. También se hizo evidente que los dos gobiernos se han centrado muy diferentes visiones de desarrollo regional y, por lo tanto, de los valores que se difunden a través de las escuelas.

PALABRAS CLAVE

política educativa; desarrollo; Amapá. 


\section{PRIMEIRAS PALAVRAS}

Nas páginas a seguir analisaremos algumas das principais inflexões nas políticas desenvolvimentistas e educacionais ocorridas no Amapá (estado situado no extremo norte do Brasil) entre 1943 e 2002. Com base na leitura atenta de fontes produzidas por agentes governamentais - entrevistas, cartilhas, artigos de jornal e relatórios -, foi possível identificar e problematizar de que forma, em diferentes momentos, a educação escolar e os projetos de desenvolvimento local e regional relacionaram-se. Dividimos o estudo dos documentos selecionados em dois momentos: começando pela análise longitudinal, na qual procuramos perceber os princípios organizadores e a sequência dos argumentos existentes no interior de cada texto; e finalizando pela análise transversal, na qual reunimos e confrotamos fragmentos de diversos escritos envolvendo os seguintes temas: desenvolvimento, política educacional e ensino. Também procuramos relacionar os textos e aos contextos, além de identificar continuidades e descontinuidades, convergências e divergências de representações e práticas dos agentes governamentais. ${ }^{1}$ Podemos adiantar que em termos de continuidade a escola, em todo o período aqui enfocado, não foi percebida como um fator de reprodução social. No tocante às descontinuidades, elas são várias e orbitam sempre em torno da definição do sentido da transformação que se deseja operar, ou seja, do modelo societal ao qual a política de desenvolvimento deve conduzir.

Abordar os desenvolvimentismos (e a relação deles com a educação) impõe a problematização da relação entre a política e a percepção que os grupos sociais têm do porvir - um tema até então pouco debatido pela historiografia. Paul Ricoeur afirma haver no conhecimento histórico um "eclipse do futuro". Esse filósofo propõe então a inclusão da futuridade no campo operatório do historiador (Ricoeur, 2007, p. 360). Em contrapartida, a crescente influência do livro Futuro passado, de Reinhart Koselleck, vem contribuindo bastante para a superação do mencionado eclipse. Esse historiador focaliza o horizonte de expectativa, que é "futuro presente, voltado para o ainda-não, para o não experimentado, para o que apenas pode ser previsto". E acrescenta: "esperança e medo, desejo e vontade, a inquietude, mas também a análise racional, a visão receptiva ou a curiosidade fazem parte da expectativa e a constituem". Segundo Koselleck, ligados intrinsecamente, passado, presente e futuro se interpelam e se remodelam reciprocamente (Koselleck, 2006, p. 309-310).

$\mathrm{O}$ período que enfocamos foi marcado pela crise da ideia de futuro que era dominante desde o Iluminismo - aquela centrada na noção de progresso. François Hartog (2003, p. 11) argumenta que a crise da noção de progresso abriu caminho para um novo regime de historicidade, ou seja, para o fim da prioridade do porvir em benefício de um autocentramento do presente, o presentismo (Hartog, 2012, p. 141-201). Ainda nesse sentido, Lucian Hölscher (2013, p. 135, tradução nossa) afirma: "o percurso da história complicou-se. $\mathrm{Na}$ atualidade, o modo como passado, presente e futuro podem ser articulados tornou-se uma questão candente da teoria

1 Sobre o conceito de representação, ver Chartier (2002). 
da história”. E completa: "os primeiros sinais de desorientação datam da Primeira Guerra Mundial, quando o que se pressupunha em termos de forças que movem a história adiante desmoronou e a fé na história como progresso tornou-se insustentável". Se a crise do otimismo em relação a um futuro percebido como progresso teve suas raízes nas duas grandes guerras do século XX, foi apenas no final da década de 1970 e no início da seguinte que ela ganhou seus mais claros contornos. ${ }^{2}$

Após ter sido profundamente abalada pelos dois últimos conflitos beligentes de escala global, a percepção do futuro enquanto progresso conseguiu recuperar o fôlego. Entre 1945 e 1973, a consolidação do modelo fordista-keynesiano possibilitou a elevação dos índices econômicos nos dois hemisférios do nosso planeta (Harvey, 2009, p. 119). A construção de grandes e sólidas estruturas de produção (como os vultosos parques industriais), a fidelização e disciplinarização do trabalho e a massificação do consumo por meio da elevação dos salários foram as diretrizes do fordismo. Por seu turno, o Estado dilatou seu campo de atuação, assumindo em diversas frentes os custos da reprodução da força de trabalho (Frigotto, 2010, p. 74-75). Apropriando-se de estratégias do socialismo real — com destaque para a planificação da economia -, o modelo fordista-keynesiano ensejou uma ampla sensação de que a humanidade, segura, seguia sua marcha rumo a um gozo de bem-estar cada vez mais generalizado. ${ }^{3} \mathrm{O}$ ocaso desses golden years começou em meado da década de 1970. Uma concorrência em escala planetária entre investidores cuja principal estratégia passou a ser a capacidade de mobilizar rapidamente seus capitais erodiu as até então sólidas estruturas fordistas. $\mathrm{O}$ aparecimento de novas tecnologias tanto tornou possível essa volatilidade inédita do capital quan-

2 É o que atestam dois diagnósticos surgidos nesse contexto: o de Jean-François Lyotard e o de Krzysztof Pomian. Em ensaio publicado originalmente em 1979, Lyotard (2015, p.XVI) chamou de pós-modernidade a incredulidade em relação às metanarrativas como as oferecidas pelo Iluminismo e pelo marxismo - , que eram até então as fontes da legitimidade do conhecimento científico. Com o advento de tal incredulidade, apenas formas precárias ou provisórias de legitimação (sujeitas a disputas acadêmicas) puderam, afirma o autor, ser adotadas pelos cientistas. No artigo "La crise de l'avenir", Pomian problematiza a emergência de um futuro opaco e muito distante de ser algo entusiasmante. Nas palavras do autor: "[atualmente] os fundamentos da civilização moderna, em todos os seus regimes, são afetados, pois é cada vez menos possível conceber um futuro que seja, a um só tempo, acessível e desejável, um porvir do qual tenhamos razões convincentes para crer que um dia chegará e que será, em vários (ou em todos) aspectos, melhor que o presente. Nós acabamos de constatar: não poderia ser pior o futuro que cremos ser o mais provável. $\mathrm{E}$ aquele que teria satisfeito a nossa expectativa encontra hoje seu último refúgio na utopia. Isso é grave, pois a nossa civilização depende do futuro tanto quanto do petróleo: com suas expectativas exauridas, ela despencará como um avião cujos motores já não mais funcionam" (Pomian, 1980, p. 4, tradução nossa). Destarte, tanto Lyotard quanto Pomian viam nessa opacidade do futuro a causa de uma grande desorientação dos sujeitos históricos no presente.

3 A esse respeito, Eric Hobsbawm (1995, p. 257, tradução nossa) destaca: "ao longo da década de 1950, muitas pessoas, sobretudo nos cada vez mais prósperos países 'desenvolvidos', tomaram consciência de que os tempos melhoravam notavelmente, principalmente quando suas memórias recorriam aos anos anteriores à Segunda Guerra Mundial". 
to ensejou o desemprego estrutural e a precarização dos vínculos trabalhistas. Nas palavras de Zygmunt Bauman (2001, p. 185), desde então "ninguém pode razoavelmente supor que está garantido contra a nova rodada de 'redução de tamanho', 'agilização' e 'racionalização', contra mudanças erráticas da demanda do mercado". A certeza do progresso cedeu lugar a uma constante insegurança. Portanto o futuro se tornou opaco, e até mesmo amedrontador, uma vez que aos riscos da escalada armamentista (no contexto da Guerra Fria) se somaram aqueles de uma catástrofe ambiental irreversível.

Percebida como região que carecia de impulsos para superar seu "atraso" socioeconômico, a Amazônia, no terceiro quartel do século XX, transformou-se em uma importante frente de avanço da modernização (aí protagonizada por grandes projetos de exploração agromineral e por agências governamentais desenvolvimentistas). Esse avanço era representado pelas classes dirigentes brasileiras como a aceleração do tempo histórico, tendo em vista a antecipação do desenvolvimento (Lobato, 2016). As experiências amazônicas relativas aos impactos da crise aqui esboçada ainda não foram consistentemente estudadas. Neste artigo enfocamos algumas delas. Analisaremos as políticas desenvolvimentistas e educacionais ocorridas no Amapá. Dois momentos serão objeto de nossa especial atenção: os governos de Janary Gentil Nunes (1944-1956) e de João Alberto Capiberibe (1995-2002). No primeiro, constatamos a realização de uma política educacional comprometida com: a estruturação de uma economia produtora de grandes excedentes comercializáveis; a máxima exploração de recursos naturais (terra, minérios e outros); a difusão de uma ética do trabalho (a formação do trabalhador virtuoso). No segundo, percebemos a realização de uma démarche no intuito de viabilizar um modelo educacional que favorecesse a substituição do "desenvolvimento predatório" pelo desenvolvimento sustentável, tendo como diretrizes: a valorização dos arranjos produtivos locais; a sustentabilidade ambiental conjugada ao manejo tecnicamente orientado dos recursos florestais; e a valorização dos modos de vida tradicionais, com seus saberes e valores.

Este artigo pretende evidenciar as relações profundas entre a educação como política pública e os horizontes de expectativa que orientam as ações governamentais no âmbito do desenvolvimento local e regional. Nas teorias clássicas, a educação é predominantemente identificada enquanto mecanismo de uma reprodução social advinda por meio da transmissão da cultura ancestral, pela difusão da ideologia dominante, ou mesmo pela naturalização dos marcadores simbólicos que legitimam as hierarquizações (Althusser, 1985; Bourdieu, 1998; Durkheim, 2007). No entanto, Otaíza Romanelli (2006, p. 29 e 84), analisando a evolução da política educacional nacional entre 1930 e 1973, argumenta que a industrialização e a urbanização brasileiras não foram acompanhadas por um movimento de expansão e modernização do ensino. Segundo a autora, essa defasagem entre educação e desenvolvimento social era gerada por um esforço das elites (os setores antidemocráticos da burguesia e os latifundiários) no intuito de manter a escola como privilégio de classe. Para Romanelli, o Estado foi um ente passivo (ou meramente reativo) na dinâmica da expansão do ensino e apenas teria respondido à pressão de uma demanda por 
mais escolas gerada pela modernização da sociedade. ${ }^{4}$ Mas as pesquisas que realizamos nos permitem inferir que o Estado brasileiro desempenhou um papel ativo em diferentes contextos, sobretudo por meio de projetos educacionais que viam a escola como um agente fundamental no processo de transformação do modo de vida dos sujeitos históricos.

\section{A POLÍTICA EDUCACIONAL JANARISTA}

No início da década de 1940, áreas de fronteira contestadas durante longo tempo preocupavam os representantes do Estado Novo. Era o caso das terras entre os rios Oiapoque e Amazonas, que foram disputadas diplomática e militarmente por franceses e brasileiros no curso de décadas e décadas. Atento aos riscos gerados pela Segunda Guerra Mundial, o governo de Getúlio Vargas criou, em 1943, os novos territórios federais, e entre eles o do Amapá. Uma vez criado o Território Federal do Amapá, era necessário escolher o seu governador. Como no caso dos interventores estaduais, a decisão cabia ao presidente da República. Dois capitães do Exército foram indicados: Emanuel de Almeida Morais e Janary Gentil Nunes. Este último, por sua experiência e reconhecida atuação no Norte, foi o escolhido por Vargas. ${ }^{5}$ No dia 25 de janeiro de 1944, em um avião da Força Aérea Brasileira,Janary Nunes chegou ao Macapá, onde aconteceu a cerimônia de instalação do governo territorial.

Durante seus doze anos de governo, que se encerraram com sua nomeação para o cargo de presidente da Petrobras, no dia $1^{\circ}$ de fevereiro de $1956,{ }^{6}$ Janary

4 Romanelli (2006, p. 70) afirma que, quanto à expansão escolar, “o Estado teve uma participação meramente passiva, tentando, quando muito, soluções de emergência diante das crises provocadas pela pressão social", e argumenta em seguida: "a demanda social de educação se transformou em fator-chave da expansão do ensino no Brasil”.

5 Janary Nunes nasceu em 1912, no município de Alenquer, no Pará. Em 1930, aos 18 anos, ingressou na Escola Militar do Realengo, no Distrito Federal (cidade do Rio de Janeiro). Entre 1936 e 1937, serviu no pelotão de Clevelândia do Norte. No ano de 1938, foi para Curitiba, Paraná, para cursar instrução no Centro de Transmissão da 5a Região Militar - no qual foi primeiro colocado. Nesse mesmo ano, publicou o livro Bandeira do Brasil. Tornou-se diretor técnico da Federação de Escoteiros do Paraná e Santa Catarina, região que na época era alvo da campanha de nacionalização das colônias de imigrantes, principalmente alemães. Em 1939, Janary Nunes foi secretário e relator da Comissão Interministerial do Exército, Marinha, Justiça e Educação, quando colaborou na elaboração do decreto-lei n. 43.545 (de 31 de julho de 1940), que regulamentou o culto aos símbolos nacionais. Janary Nunes assumiu, em 1940, o comando

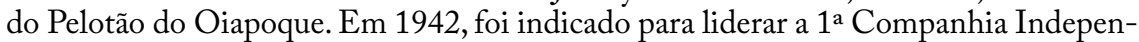
dente de Metralhadoras Antiaéreas, responsável pela defesa da Base Aérea de Belém, durante a Segunda Guerra Mundial. E, em 27 de dezembro de 1943, foi nomeado governador do Território Federal do Amapá (Benevides, 1946, p. 75-76).

6 Durante a maior parte do ano de 1949, Janary Nunes ficou afastado do cargo de governador do Amapá com o objetivo de realizar curso para obter nova patente militar. $\mathrm{O}$ caráter interino desse afastamento e do governo de seu substituto (Raul Montero Valdez) — bem como a manutenção das diretrizes janaristas — invalida qualquer tentativa interpretativa de identificar nesse ano uma interrupção da política que se estava implementando no Amapá desde 1944. 
procurou evidenciar que o dia 25 de janeiro de 1944, data de sua posse, foi um marco histórico que dividiu em dois momentos radicalmente distintos a história das populações do Território Federal do Amapá. A cada dia 25 de janeiro ocorriam atividades como: apresentações estudantis, campeonatos esportivos, inaugurações, churrascos, passeios e bailes. Comumente, o jornal governamental, Amapá, apresentava nesse dia edições especiais, com um número maior de páginas ou vários cadernos com fotos e crônicas acerca das principais realizações do governo. Desse modo, em âmbito local ocorria a tentativa do estabelecimento de uma narrativa histórica, na qual a posse de Janary representava para os amapaenses o fim de um período de pessimismo, abandono, caos, atraso, doenças, analfabetismo, superstição, pobreza e invisibilidade. Iniciava-se então, segundo esse discurso, um luminoso momento de otimismo, patriotismo, progresso em todos os aspectos socioeconômicos. ${ }^{7}$

$\mathrm{O}$ projeto político janarista não tinha como meta meramente responder às demandas internas da sociedade amapaense. Seu objetivo era mais ambicioso: reorganizar a vida com base em novos valores e hábitos. O papel ativo do Estado no processo de modernização da sociedade brasileira manifestou-se de forma mais ostensiva e ampla no Amapá. Na Amazônia, de maneira geral, as intervenções do Estado Novo ocorreram em várias frentes e as demandas ou necessidades regionais muitas vezes não coincidiam com a perspectiva predominantemente esposada pelos agentes estatais. A valorização da produção de mercado levava muitos técnicos e políticos a reprovarem a falta de ambição (de acumular riquezas) do ribeirinho, que, via de regra, produzia principalmente para o próprio consumo. ${ }^{8}$ As práticas tradicionais de cultivo e de extrativismo florestal das populações locais eram classificadas como primitivas e inadequadas à aceleração do crescimento dos índices econômicos. As comunidades rurais amapaenses foram convocadas a abandonar sua cultura (desdenhando-a como atrasada) em nome da consolidação do capitalismo nacional, via integração de subsistemas agroindustriais.

O governo federal, a partir de 1930, procurou ordenar as relações sociais e produtivas no Brasil com base na ética do trabalho, que condenava o gozo despreo-

7 Como exemplo, destacamos um trecho do Editorial de número especial do jornal Amapá, de 25 de janeiro de 1952: "se o Amapá caminhou mais célere do que outros recantos do país, projetando-se em evidência no cenário econômico e social da Pátria, deve-se ao entrosamento produtivo entre o seu Governo e o seu povo, que sempre marcharam unidos na árdua e gloriosa missão de soerguimento do Território. Foi graças a essa coesão de ideais que nasceu e cresceu, florindo e frutificando, a mística do Amapá, tornando esta terra de heróis e de sofrimentos, numa das mais promissoras esperanças do Brasil atual" (“Oito anos de batalha territorial”, Amapá, 1952, p. 1).

8 Janary, em 1946, conclamava todas as categorias de trabalhadores a colaborarem na conversão do homem local: "precisamos reagir contra esse vício que bem revela o desprezo pela produção. Há falta de ambição e de eficiência. Combatamos essa tara de nosso caráter e de nossa formação. De nada adiantará o esforço isolado. Levemos para a barraca do agricultor, do seringueiro, do pescador, do castanheiro, para todos os lares da Amazônia, dos que moram nas cidades, dos que se juntam em torno dos 'barracões' ou dos isolados nas beiras dos rios sob a sombra da selva - a evidência da necessidade de produzir mais. Esse será o caminho da redenção do nosso caboclo e do levantamento do nível de vida do povo brasileiro" (Nunes, 1943). 
cupado do tempo livre, e valorizava o tempo produtivo, gasto no labor (agora não mais associado ao estigma da escravidão, mas ao ideal de prosperidade da família e da pátria). ${ }^{9}$ No início dos anos de 1930 , formou-se uma atmosfera de grandes mudanças na sociedade brasileira, cujo substrato era o processo de urbanização e de industrialização e a nova política de desenvolvimento social que o Estado engendrava no Brasil. Nesse novo quadro, as teorias raciológicas tornaram-se obsoletas. $O$ projeto varguista de criação de um novo homem nacional não se fundamentava na busca do branqueamento ou da imigração, mas na ampliação do intervencionismo do Estado para áreas como educação e medicina social. ${ }^{10} \mathrm{Ou}$ seja, as diretrizes do governo federal do pós-30 não mais se baseavam na ideia de que o atraso socioeconômico brasileiro era causado pela inferioridade racial do mestiço. A formação profissional e a organização de um mercado de trabalho nacional eram as bases de uma política que tinha como objetivo ampliar ao máximo o acesso dos brasileiros aos bens de consumo. Por exemplo, a Lei dos $2 / 3$ (decreto n. 19.482) obrigava as empresas a empregarem trabalhadores nacionais nessa proporção. Medidas governamentais passaram a limitar a entrada de estrangeiros no país. $\mathrm{O}$ artigo 121, parágrafo $6^{\circ}$, da Constituição de 1934 instituiu um regime de cotas imigratórias (Gomes, 1982, p. 154-155, 162).

O otimismo nacionalista do pós-30 tinha como cerne a crença na viabilidade da construção no Brasil de uma nação moderna valendo-se de forças produtivas internas. E foi dentro de uma atmosfera de otimismo nacionalista e de centralização política que os novos territórios federais (Amapá, Rio Branco, Guaporé, Ponta Porã e Iguaçu) foram criados em 1943. O novo projeto governamental de expansão da fronteira da modernização carecia de instrumentos poderosos para fazer frente a hábitos seculares. Ao lado do otimismo nacionalista, ganhava força um otimismo em torno da educação, que era considerada o mais eficaz mecanismo para retirar o homem brasileiro do estado de amesquinhamento em que era visto. Acreditava-se que a educação era o melhor meio de formar um novo homem - capaz de se orientar conforme a racionalidade capitalista em benefício de si e da nação.

Esse otimismo em relação à educação já podia ser observado na Primeira República. Jorge Nagle argumenta que a desilusão com a República ensejou um movimento de "republicanização da República", algo que era visto como possível por meio da difusão do processo educacional. Os pensamentos em voga atribuíam à ignorância todas as crises e viam na instrução a solução de todos os problemas sociais, econômicos, políticos e outros. Para Nagle, "a percepção 'romântica' dos

9 Mesmo no Sudeste, as demandas relativas à modernização não representavam o interesse de toda a sociedade. A valorização do trabalho regular e a disciplinarização da vida de homens e mulheres entrava em choque com a chamada cultura da malandragem (Tota, 2001, p. 45-49; Vasconcellos e Suzuki Júnior, 1984, p. 501-523).

10 Como destaca Janete M. Lins de Azevedo (2004), as políticas públicas são construídas "a partir das representações sociais que cada sociedade desenvolve a respeito de si própria. Segundo esta ótica, as políticas públicas são ações que guardam intrínseca conexão com o universo cultural e simbólico ou, melhor dizendo, com o sistema de significações que é próprio de uma determinada realidade social” (Azevedo, 2004, p. XIV). 
problemas da sociedade brasileira e de suas soluções resulta numa superestimação do processo educacional regenerador do homem". Isso teria raízes em uma inversão da ordem das coisas: "as relações básicas da sociedade brasileira deslocam-se para um plano derivado" (Nagle, 2004, p. 262). Um programa amplo de transformação social estaria sendo substituído por um programa restrito à formação — aperfeiçoamento e disseminação da educação escolar. ${ }^{11}$

A política educacional janarista objetivava revigorar o homem regional para que ele pudesse ajudar a alavancar o desenvolvimento do país. São numerosos os momentos em que Janary reafirmou a importância da educação no conjunto de suas intenções para o destino do Amapá. O seguinte fragmento é um exemplo:

a Educação terá de constituir fator preponderante, adotando as formas mais intensas e variadas para a conquista de aperfeiçoamento.

No Amapá ela terá de intervir em todos os setores de atividades: alfabetizando, porque, se aprender a ler e contar não constitui sua finalidade, é, pelo menos, o processo inicial mais necessário para atingi-la; divulgando as regras higiênicas e sanitárias e criando a mística do caboclo sadio para combater o conformismo à doença; executando processos novos de cultura da terra, de assistência à criação; de organização administrativa e social; lutando contra o nomadismo, a casa miserável, a família sem tradição, o pauperismo; prégando a fixação ao solo e exemplificando com fatos a possibilidade de ser feliz na cidade ou no interior; propagando o dever de satisfazer os compromissos comerciais, o instinto da economia e o amor ao trabalho; ensinando a alimentação, o vestuário, o exercício, a alegria, o conforto, a crença; incutindo em cada indivíduo a noção de que pertence à coletividade brasileira; difundindo as diretrizes da géopolítica nacional de fórma simples e acessível, para que se tornem cogitação popular; plasmando a ânsia de melhorar seu corpo, sua família e sua pátria. (Nunes, 1947)

Esse entusiasmo pela educação se materializaria por meio da abertura de várias frentes de ação. As linhas antes citadas nos autorizam inferir que a educação que se desenvolvera nas terras amapaenses a partir de 25 de janeiro de 1944 fazia parte de um ambicioso projeto governamental de transformação dos modos de vida dos brasileiros. Angela de Castro Gomes argumenta que "a invenção do Estado Novo, fixando os postulados pedagógicos fundamentais à educação dos brasileiros, tinha em vista uma série de valores dentre os quais o culto à nacionalidade, à disciplina, à moral e também ao trabalho" (Gomes, 1982, p. 158). A classe dirigente de modo geral atribuía ao ensino a tarefa de dotar o capital humano nacional das habilidades necessárias à modernização econômica do país. Por meio do trabalho, o homem teria amplo acesso aos bens de consumo e colaboraria para

11 Marta Maria Chagas de Carvalho apresenta a seguinte objeção a essa tese: o entusiasmo pela educação era romântico, mas, diferentemente do que pensava Nagle, "o romantismo do projeto de unidade e unificação" era uma tática essencial à construção e consolidação de uma hegemonia cultural (Carvalho, 1997). 
o enriquecimento da nação. Como preparação para o mundo do trabalho, o ensino não poderia ser homogêneo, uma vez que o projeto de constituição de uma relativa autonomia econômica nacional pressupunha a formação de um amplo mercado interno, baseado na interação entre áreas colonizadas e industrializadas — ou seja, uma divisão regional do trabalho.

Dentro da política educacional implantada no território do Amapá nas décadas de 1940 e 1950, a proposição da ruralização do ensino (primário) foi o elemento norteador. Segundo a classe dirigente territorial, as crianças deveriam ser preparadas para integrarem o mundo da produção, por meio da qual se integrariam a própria sociedade. ${ }^{12}$ Esperava-se que o professor exercesse forte influência sobre cada aluno, "transformando e orientando seus métodos de vida" "O professor rural", Amapá, 1952). A política educacional janarista objetivava revigorar o homem regional para que ele pudesse ajudar a alavancar o desenvolvimento do país. $\mathrm{O}$ amor ao trabalho e a melhoria das condições gerais de vida se refletiriam no aprimoramento do corpo, da família e da nação. Portanto, o ensino rural, sem prejuízo de suas especificidades, fazia parte de um amplo planejamento cujo objetivo era a formação de um novo homem, plenamente adequado às exigências da modernização econômica, da consolidação do capitalismo nacional. A produção rural ultrapassaria os limites da subsistência, gerando um excedente regional que abasteceria os centros urbanos do Brasil. A integração nacional seria resultado do trabalho de fazer coincidir a fronteira econômica com a fronteira política.

\section{O PDSA E O PROJETO ESCOLA BOSQUE DO AMAPÁ}

A política educacional de Janary Nunes era um componente básico do projeto de desenvolvimento, que na visão desse governante iria tirar o Amapá do "atraso" socioeconômico. No conjunto das ações realizadas, à produção agrícola em escala comercial viria se juntar o primeiro grande projeto de exploração mineral da Amazônia, ou seja, a extração de milhares de toneladas de manganês do centro do território amapaense pela Icomi, indústria da área mineradora. Segundo Nunes, o aproveitamento das jazidas manganíferas do Vale do Rio Amapari era um vetor da autonomia financeira amapaense, "porque era capaz de produzir recursos no local, e [de] fornecer os meios indispensáveis para as obras estruturais de que a região necessita, a fim de criar uma economia própria, estável, definitiva, e concorrer, com saldos substanciais, no balanço de pagamento do País" (Nunes, 1959, p. 7). Essa percepção otimista em relação à capacidade de os grandes projetos alavancarem o desenvolvimento regional entrou em crise nos anos de 1980. Porém, como demonstraremos adiante, isso não resultou no desaparecimento definitivo dessa perspectiva.

12 Em 1947, afirmou o então diretor da Divisão de Educação, Marcílio Vianna: "A escola rural, antes de mais nada, precisa ser um aparelho educativo organizado em função da produção. E, logicamente, organizada em função da produção do meio a que serve. Impossível separar a educação da produção" (Viana, 1947). 
O naufrágio do barco Novo Amapá - que emergiu superlotado nas águas do Rio Cajari, em 6 de janeiro de 1981, levando a óbito mais de trezentas pessoas que viajavam de volta do trabalho na empresa Jari Celulose - pode ser adotado como trágica epígrafe dessa crise (Capiberibe, 1981, p. 65-67). Segundo Danilo Pacheco, os grandes projetos instalados no Amapá tornaram-se os alvos prediletos das críticas da literatura do naufrágio. De acordo com tal produção literária, "ao se pensar na integração da Amazônia e na atração de investimentos estrangeiros, visou-se tão somente o lucro", ou seja, "negligenciaram a segurança dos trabalhadores de uma região que não estava preparada para receber uma crescente demanda de migrantes, que aí vieram buscar empregos e tentar transformar em realidade o sonho de uma nova vida melhor" (Pacheco, 2016, p. 52-53). Portanto, a falência financeira do Projeto Jari, ocorrida no contexto do ocaso do fordismo, foi antecedida por uma derrocada moral. Ao lado da denúncia dos negativos impactos sociais causados pelo velho modelo de desenvolvimento, ganhava força nos debates promovidos pelas agências internacionais a tese de que era necessária e urgente a criação de formas de produção econômica que não destruíssem a natureza.

Acidentes envolvendo usinas nucleares e contaminações tóxicas de grandes proporções - por exemplo, os casos: Three Mile Island (Estados Unidos), em 1979, Love Canal (estado de Nova York, Estados Unidos), em 1980, Bhopal (Índia), em 1984, e Chernobyl (então União das Repúblicas Socialistas Soviéticas), em 1986 - concorreram para o aparecimento da noção de sociedade de risco. Segundo Ulrich Beck (2011, p. 10), "na globalidade da contaminação e nas cadeias mundiais de alimentos e produtos, as ameaças à vida na cultura industrial passam por metamorfoses sociais do perigo: regras da vida cotidiana são viradas de cabeça para baixo". Essas palavras foram escritas e publicadas em um contexto no qual os problemas ambientais passam a ser analisados e debatidos em escala planetária. Nas décadas de 1970 e 1980, os riscos globais e de consequências de longo prazo tornaram-se tema de vários eventos internacionais de cunho político e científico. Dentro desses debates emergiram propostas de controle dos agentes da degradação ambiental (principalmente econômicos) e de difusão das informações relativas à urgência da preservação da natureza vis-à-vis as ameaças crescentes. O trabalho do Clube de Roma, Limites do crescimento em 1972, chamou a atenção de políticos e intelectuais para a pressão que o crescimento demográfico mundial exercia sobre os limitados recursos naturais. Também a Conferência de Estocolmo (1972) difundiu a crítica ambientalista ao modo de vida contemporâneo, destacando a necessidade de harmonização entre a melhoria dos níveis de qualidade de vida e a preservação ambiental. Segundo Pedro Jacobi, "a maior virtude dessa abordagem é que, além da incorporação definitiva dos aspectos ecológicos no plano teórico, ela enfatiza a necessidade de inverter a tendência autodestrutiva dos processos de desenvolvimento no seu abuso contra a natureza" (Jacobi, 2003, p. 193).

Conhecido como Nosso futuro comum, o Relatório Brundtland (1987) defendeu, em substituição da noção de ecodesenvolvimento — que preceituava a gestão racional e responsável dos recursos naturais (Sachs, 1986) - , a ideia de desenvolvimento sustentável, ou seja, um modelo de desenvolvimento viável tanto ecológica quanto economicamente (Sorrentino et al., 2005, p. 289). Nesse contexto, a luta 
dos chamados povos da floresta contra o avanço da frente agropastoril na porção acreana da Amazônia ganhou prestígio nacional e internacional. Os assassinatos dos líderes de seringueiros Wilson Pinheiro (1980) e Chico Mendes (1988) repercutiram amplamente, provocando uma crescente pressão, originada de fora do Brasil, para que o governo brasileiro criasse medidas capazes de barrar o desflorestamento, mas também de restringir ou disciplinar o uso dos recursos florestais (Basílio, 2001; Souza, 1996). João Alberto Capiberibe (Capi), criador do Programa de Desenvolvimento Sustentável do Amapá (PDSA), apesar de ter trabalhado como subsecretário de desenvolvimento rural do município acreano de Cruzeiro do Sul, não conheceu pessoalmente Chico Mendes. Foi apenas após o trágico assassinato desse líder que Capi começou a se familiarizar com as propostas defendidas pelos seringueiros do Acre.

O PDSA não nasceu como a deusa Atena. Ou seja, ele não saiu pronto da cabeça de Capiberibe. Como ele próprio admitiu, tal programa foi antecedido por diversas experiências ou por ensaios pontuais - quando ele foi secretário de agricultura do Amapá (1985) e durante sua gestão na prefeitura de Macapá, entre 1985 e 1992. No final de 1992, ano em que ocorreu a Conferência Rio-92, Capiberibe montou um grupo de trabalho que passou a estudar o documento Nosso futuro comum e a debater como aplicar as ideias aí existentes na realidade amapaense. Quando ganhou as eleições para governador, Capiberibe já havia delineado as diretrizes mais gerais do programa. Ainda assim, no início de sua gestão no governo do estado, Capi contou com a importante colaboração de Mary Allegretti, que havia assessorado Chico Mendes (no Acre) ao longo dos anos de 1970 e 1980 e que deixou o cargo de consultora do Banco Mundial em Washington para assumir a secretaria de planejamento do estado do Amapá. A respeito do processo de construção do PDSA, Capiberibe afirmou em entrevista publicada em 2000 que ocorreu um intenso e penoso debate acerca da escala de sua aplicação: realizar primeiro projetos pontuais ou envolver todas as áreas do governo e da sociedade em amplas frentes de trabalho? Outro aspecto destacado pelo governador diz respeito ao fato de as questões relativas aos impactos sociais terem sido gradualmente inseridas no programa de governo - o que adveio, em parte, da pressão de grupos da sociedade, como castanheiros e ribeirinhos (Moulin, 2000, p. 104-105). Colaborador assíduo de João Alberto Capiberibe, o jornalista Elson Martins pôs em evidência a ruptura que o PDSA pretendia promover em relação ao modelo de desenvolvimento anteriormente hegemônico.

O Amapá foi o melhor exemplo, na Amazônia, da concentração de megaprojetos equivocados que se fundamentam no esgotamento dos recursos naturais sem agregação de valor e [que] não levam em conta os interesses das populações locais: Icomi (exploração de manganês), Novo Astro (ouro), Brumasa (madeira), Projeto Jari (celulose), Cadam (caulim) constituem modelos de desenvolvimento que não cabem na nova realidade do Amapá sustentável. Em contraposição a esses projetos, surgem as cooperativas de castanheiros, as cooperativas-empresas de pescadores de camarão, as joint-ventures com parceiros internacionais para exploração do palmito e do mel silvestre do Bailique, o 
ecoturismo pensado e gerido pelas comunidades, a produção de fitoterápicos e tantas novidades que podem surgir com entusiasmo de uma economia nativa sintonizada com a biotecnologia e os modernos mercados do mundo. (Moulin, 2000, p. 21-22)

Tentava-se então deixar para trás um modelo de desenvolvimento local e regional que havia sido implantado na Amazônia na década de 1940 e que ganhara bastante força (por meio de volumosos investimentos estatais) durante a ditadura civil-militar (Araújo, 1996, p. 21). ${ }^{13}$ Para o pensamento desenvolvimentista que se fortaleceu no pós-guerra, o discurso ambiental representava um obstáculo ao crescimento econômico. Em contrapartida, tal crescimento foi por muito tempo considerado a solução dos problemas sociais do Brasil. No contexto do "milagre brasileiro" (1969-1973), a preservação ambiental era percebida pelas classes dirigentes como uma interferência indesejada. Por isso, na Conferência Internacional da Organização das Nações Unidas sobre o Meio Ambiente, realizada no ano de 1972, em Estocolmo, a delegação do governo brasileiro liderou a frente dos países periféricos em defesa do crescimento industrial e contra aquilo que ela, a frente, via como um conjunto de manobras dos países centrais para barrar o desenvolvimento da periferia do mundo industrializado (Lima, 2009, p. 151).

No contexto da redemocratização, grupos políticos do Acre e do Amapá associaram a proposição da substituição do modelo hegemônico de desenvolvimento econômico - que havia, por décadas, norteado discursos e investimentos - aos ataques às heranças autoritárias do regime ditatorial do pós-64. No Amapá, para que os princípios e valores que embasavam o PDSA ganhassem capilaridade social, uma política educacional centrada na educação ambiental foi concebida. Sob a influência da Rio-92, rechaçava-se nesse programa uma educação ambiental meramente conservacionista, que entendesse o homem como um incorrigível adversário da natureza. A ideia de se implantar tal modelo educacional no Amapá baseava-se no consenso em torno da necessidade de uma educação sensível aos saberes e modos de vida locais (especialmente de indígenas, quilombolas e ribeirinhos), bem como em torno da importância de se buscar a harmonização entre o desenvolvimento socioeconômico e a sustentabilidade natural. Agrônomos, biólogos, professores, pedagogos, técnicos agrícolas e demais representantes da sociedade local envolvidos nos primeiros debates sobre o PDSA definiram a educação ambiental não como a simples "defesa da ecologia", mas sim como a construção de saberes que auxiliassem na compreensão de como todas as dimensões da vida humana (econômica, social, cultural e política) afetam e são afetadas pelo meio ambiente. Rejeitava-se, dessa forma, a abordagem episódica ou esporádica — realizada apenas em algumas disciplinas e datas (como o Dia do Índio e o Dia da Árvore) - de educação ambiental. Esta era então percebida como o ponto de articulação de um trabalho interdisciplinar e permanente (Araújo, 1996, p. 11-18, 24, 28).

13 A respeito dos grandes projetos econômicos implantados na Amazônia durante o período ditatorial existe farta literatura. Destacamos: Becker (1994), Brito (2001) e Huertas (2009). 
No Encontro Estadual de Educação Rural e Desenvolvimento Sustentável, ocorrido em dezembro de 1995, o sociólogo José Mariano Klautau de Araújo apresentou aos amapaenses, por meio de vídeo e palestra, o Projeto Escola Bosque, já por ele implantado na ilha de Caratateua (Belém, Pará). Assim, tendo em vista a adaptação desse projeto à realidade do Amapá, foi montado um grupo de trabalho. Ao apresentar sua filosofia pedagógico-ambiental, Klautau de Araújo criticou as inciativas que no passado se baseavam na "ideologia do progresso a qualquer preço, na concepção e uso da natureza e de seus recursos como infinitos, de resultados econômicos de prazo curtíssimo, de efeito concentrador de riquezas reinvestidas fora da região"(Araújo, 1996, p. 11 e 21). O objetivo da disseminação da educação ambiental por meio de escolas bosques era incutir na sociedade local as ideias e os valores que constituíam os fundamentos tanto da adoção do PDSA quanto da rejeição do modelo de desenvolvimento então em crise. Mais especificamente, pretendia-se: formar profissionais capazes de colaborar na sustentabilidade socioeconômica do Amapá; introduzir a metodologia socioambiental no ensino das matérias tradicionais, "partindo da natureza, do saber local ao universal"; propiciar experiências formativas que levassem ao resgate e à preservação do meio ambiente; e adequar o currículo escolar à educação ambiental, "reorientando e articulando as diversas disciplinas e experiências educativas”(Governo do Estado do Amapá, 1997a, p. 2).

Após estudo prévio, decidiu-se construir o Centro de Referência em Educação Ambiental (sede principal das escolas bosques amapaenses) na ilha de Santana. ${ }^{14}$ Além da proximidade de uma infraestrutura urbana - que garantia acesso à energia elétrica, à comunicação e ao comércio -, outro fator que concorreu para que a escolha recaísse sobre essa ilha foi a coexistência nela de áreas de relativa preservação ambiental com aquelas já devastadas. Os técnicos do governo destacavam que "esta convivência de certo modo é rica para educação ambiental, porque 'compara' as formas de agir do homem e estabelece, pela recuperação das áreas degradadas, de forma prática, como aula de campo, o ato de conhecer as relações homem/natureza" (Governo do Estado do Amapá, 1997d). Na ilha de Santana foram realizados vários encontros para se discutir com os moradores a definição da estrutura e do funcionamento da futura escola. A elaboração participativa das estratégias de adequação do projeto era estandardizada como uma forma de revigoramento do ainda "frágil exercício da democracia". Essa fragilidade era apontada como uma desafiadora herança da ditadura. Percebemos, nesse atinente, alguns ecos dos postulados de Paulo Freire, autor que defendia uma educação dialógica e emancipadora (Freire, 2005). Araújo (1996, p. 40), por exemplo, destacava que "as reuniões de rotina entre governo, técnicos, pesquisadores e população para decidir desde a mais simples opinião até a escolha de disciplinas e currículos, na verdade são um exercício de cidadania sobre como planejar uma educação libertadora". Contudo, as alusões às ideias freirianas eram incidentais e sem grandes consequên-

14 A ilha possuía 1.323 habitantes, distribuídos por 2.114 hectares com três ecossistemas (várzea, floresta e cerrado) relativamente bem preservados e entrecortados por diversos igarapés. 
cias no âmbito da definição das diretrizes gerais do projeto. Pois, enquanto Freire problematizava centralmente a relação homem/homem (a fricção entre práticas opressivas e libertadoras), a educação ambiental proposta no governo de Capiberibe centrava-se nas interações entre homem e natureza.

Esperava-se que cada escola bosque funcionasse como uma "agência difusora das ações educativas visando a uma conduta responsável dos indivíduos em relação ao meio ambiente e pautada na proposta de desenvolvimento sustentável do Amapá" (Araújo,1996, p. 58). Módulos regionais formariam um sistema capitaneado pela Escola Bosque da Ilha de Santana (centro de referência). O projeto de socialização da escola bosque previa a construção de unidades escolares nas seguintes localidades: Bailique, Cajari, Iratapurú, Santo Antonio, Padaria, Maracá, Aporema e Tartarugalzino (Governo do Estado do Amapá, s/d., p. 5-6). Essas escolas, além da educação infantil, dos ensinos fundamental e médio comum, ofereceriam cursos de formação de técnicos em educação ambiental e de professores. Esses últimos, "residentes nas próprias comunidades", seriam os garantidores de uma educação fundamentada no conhecimento das realidades de cada lugar (Governo do Estado do Amapá, 1997c, p. 5-6). Porém os documentos oficiais não indicam de que modo professores formados no meio urbano poderiam ser agentes eficazes de uma educação ambiental planejada para sociedades com características predominantemente rurais, nem como professores formados nas escolas bosques poderiam levar esse tipo de educação para as cidades (Centro Amapaense de Atividades Culturais, Econômicas e Sociais, 2000, p. 17).

A aplicação do PDSA nos centros urbanos também não foi consistentemente debatida pelos agentes governamentais. Como destacou Bertha Becker (1996), a noção de desenvolvimento sustentável apontava para a adoção de estratégias de conservação ambiental e de participação de comunidades locais (pequenos produtores) na definição dos usos da terra. A autora argumentou que esse viés rural contrastava com a realidade do Brasil em geral e da Amazônia em particular, sendo esta uma "selva urbanizada", já com 51,8\% de habitantes urbanos em 1980. No atinente à formação de professores, José Mariano Klautau de Araújo afirmou:

os professores formados pela Escola Bosque deverão prioritariamente suprir as necessidades das escolas da zona rural do estado e em alguns casos em regime de carência atender às escolas de zona urbana, desse modo se estará estendendo a filosofia pedagógico ambiental em todo estado. (Araújo, 1996, p. 81)

Apesar de Araújo privilegiar a zona rural nesse percurso de difusão, na década 1990 a maioria da população amapaense vivia em cidades pequenas e médias. Ademais, no final do século passado, um vultoso fluxo de migrantes - que se deslocavam em busca das frentes de trabalho abertas pela transformação do Amapá em estado, despontando com concursos públicos e construções, e pela criação da Área de Livre Comércio de Macapá e Santana - acelerou bastante o aumento do percentual de população urbana nessa unidade da federação (Diocese de Macapá, 1995).

No entanto, o método socioambiental não ganhou contornos claros, que possibilitassem aos professores das várias disciplinas empregarem-no com de- 
senvoltura e perspicácia (Governo do Estado do Amapá, 1997b). Na verdade, a noção de desenvolvimento sustentável que orientava o PDSA e o Projeto Escola Bosque era muito inconsistente. Gustavo Lins Ribeiro (1991, p. 64-65) destaca que o debate em torno do ambientalismo oscilava entre extremos que adotavam percepções divergentes em relação à futuridade. Nas palavras do autor: "não deixa de ser curioso que o ambientalismo, tanto em suas versões fundamentalistas mais conservadoras (como o conservacionismo), quanto nas versões que negociam com a ideia de desenvolvimento, tenha o futuro como elemento central da sua arquitetura interpretativa". E completa: "numa vertente, pela ameaça ao fim da vida e do planeta, o que já lhe valeu a designação de ecoapocaliticismo; noutra, pela esperança de reformar a lógica desenvolvimentista”. Segundo Ribeiro, a noção de desenvolvimento sustentável sinalizava para a compatibilização do que parecia incompatível: crescimento econômico e preservação da natureza. Seus defensores, de modo geral, apontavam para a urgência de se reformar o ideário centrado na utopia do progresso, submetendo a lógica do mercado aos imperativos da sustentabilidade ambiental. Noção polissêmica e em construção, ela foi apropriada de diversos modos e por diferentes grupos, como outros estudos já apontaram (Ribeiro, 1992, p. 28-30).

O PDSA e o Projeto Escola Bosque foram interrompidos antes de se consolidarem enquanto política pública. Em 2003, ao assumir o governo do Amapá, Waldez Góes rejeitou a possibilidade de prosseguir com as diretrizes do desenvolvimento sustentável, adotando o discurso de que esse modelo havia sido o responsável pelo desaquecimento da economia local. O governo amapaense voltou então a ter como meta a alavancagem dos índices econômicos por meio de grandes empreendimentos agropecuários e industriais. Nas escolas bosques, a educação ambiental feneceu, dando lugar a uma proposta curricular em nada diferente daquela usada nas demais unidades escolares (Ratier, 2015). Observamos então a vigência de um ziguezague, de um sentido sinuoso, que confirma ser a descontinuidade de uma característica estrutural da política educacional brasileira (Saviani, 2008, p. 11). Política que é um campo de disputas entre grupos que são guiados por diferentes horizontes de expectativas.

\section{PALAVRAS FINAIS}

No Amapá, em meado da década de 1990, ensaiou-se uma ruptura profunda com o modelo de desenvolvimento econômico que fora hegemônico regionalmente desde a metade do século XX. No lugar dos grandes projetos que geravam uma riqueza concentrada e escoada para fora do Brasil, o PDSA pretendeu valorizar os pequenos e médios arranjos produtivos locais por meio do incentivo ao associativismo e da agregação de valor à produção de extrativistas, artesãos, pescadores e outros (Governo do Estado do Amapá, 1997c, p. 2-3). Esse novo modelo de desenvolvimento, na perspectiva do governo de Capiberibe, exigia uma política educacional comprometida com a difusão da educação ambiental. Para tanto, concebeu-se o Projeto Escola Bosque do Amapá, cujas linhas gerais foram aqui apresentadas.

A análise de tal inflexão pôs em evidência fortes relações históricas entre projetos de desenvolvimento e políticas educacionais. Nos dois modelos educacio- 
nais enfocados a educação não era pensada como um mecanismo de reprodução social. A escola deveria ser, em ambos, um espaço de geração e fomento de novas formas de percepção da realidade e de novos modos de agir. No tocante à política educacional janarista, a meta era a formação de um trabalhador disciplinado, apto a colaborar no aumento da produção local, a fim de que esta gerasse volumosos excedentes comercializáveis. Diferentemente, a educação ambiental estandardizada por Capiberibe valorizava a produção em pequena e média escala e que, principalmente, respeitasse a natureza, adotando o manejo dos recursos naturais. A harmonização entre desenvolvimento econômico e preservação do meio ambiente era defendida com base no argumento de que a economia predatória dos grandes projetos era causadora de ampla exclusão social e de fortes impactos ambientais.

Este artigo aponta igualmente para o fato de que a passagem de um modelo predatório de política desenvolvimentista a outro baseado na diretriz da sustentabilidade foi possível graças ao aparecimento de um novo horizonte de expectativas para a Amazônia, surgido depois da crise do fordismo, da ocorrência de grandes desastres ambientais e do consequente debate sobre o futuro do planeta Terra. Nos círculos de discussão entre intelectuais e políticos, a percepção de que o sentido dado às sociedades pelo capitalismo era o progresso do bem-estar humano passou a disputar cada vez mais espaço com o entendimento de que esse modo de produção levaria a humanidade a uma irreversível hecatombe de escala global. Portanto, a noção de que existe um crescente risco planetário ganhou força nas últimas décadas, possibilitando o aparecimento e a legitimação de políticas educacionais centradas no esforço de difusão da educação ambiental. A nova consciência ambiental era, por sua vez, percebida como aquilo que tornaria possível o retorno do otimismo em relação ao progresso da humanidade, agora identificado como um processo de desenvolvimento econômico harmonizado com a sustentabilidade dos ecossistemas.

\section{REFERÊNCIAS}

Althusser, L. Aparelhos ideológicos de Estado: nota sobre os aparelhos ideológicos de Estado. 2. ed. Rio de Janeiro: Graal, 1985.

Araújo, J. M. K. Projeto Escola Bosque. Macapá: Governo do Estado do Amapá, 1996. Azevedo,J.M.L.A educação como política pública.3. ed.Campinas: Autores Associados, 2004. Basílio, S. T. C. A luta pela terra e a Igreja católica no Vale do Purús (1970-1980).2001.201f. Tese (Doutorado em História) - Universidade Federal de Pernambuco, Recife, 2001.

Bauman, Z. Modernidade líquida. Rio de Janeiro: Jorge Zahar, 2001.

Beck,U. Sociedade de risco: rumo a uma outra modernidade.2.ed. São Paulo: Editora 34, 2011. Becker, B. K. Amazônia. 3. ed. São Paulo: Ática, 1994. . Geografia e meio ambiente no Brasil. São Paulo: Hucitec, 1996.

Benevides, M. A. Os novos territórios federais. Rio de Janeiro: Imprensa Nacional, 1946. Bourdieu, P. Escritos de educação. Petrópolis: Vozes, 1998.

Brito, D. C. A modernização da superfície. Belém: UFPA; NAEA, 2001. 
Capiberibe, J. A. Morte nas águas: tragédia do Cajari. Recife: M. Magalhães Composições Gráficas, 1981.

Carvalho, M. M. C. Educação e política nos anos 20: a desilusão com a República e o entusiasmo pela educação. In: De Lorenzo, H. C.; Costa, W. P. (Orgs.). A década de 1920 e as origens do Brasil moderno. São Paulo: UNESP, 1997.

Centro Amapaense de Atividades Culturais, Econômicas e Sociais. Bailique: desenvolvimento sustentável no delta do Amazonas. Macapá: GEA, 2000.

Chartier, R.A história cultural: entre práticas e representações. 2. ed. Lisboa: Difel,2002.

Diocese de Macapá. As migrações em Macapá e Santana: sua realidade econômica, social, política e religiosa. Macapá: Diocese de Macapá, 1995.

Durkheim, É. Educação e sociologia. Lisboa: Edições 70, 2007.

Freire, P. Pedagogia do oprimido. Rio de Janeiro: Paz e Terra, 2005. [1. ed. 1968].

Frigotto, G. Educação e a crise do capitalismo real. 6. ed. São Paulo: Cortez, 2010.

Gomes, A. C. A construção do homem novo: o trabalhador brasileiro. In: Oliveira, L. L.; Velloso, M. P.; Gomes, A. C. (Orgs.). Estado Novo: ideologia e poder. Rio de Janeiro: Zahar, 1982. p. 151-166.

Governo do Estado do Amapá. Projeto Escola Bosque do Amapá: Centro de Referência em Educação Ambiental da Ilha de Santana. Macapá: GEA, s/d.

. Projeto Escola Bosque do Amapá: aspectos pedagógicos. Macapá: GEA, 1997a. . Projeto Escola Bosque do Amapá: o método socioambiental. Macapá: GEA, 1997b. . Projeto Escola Bosque do Amapá: módulo regional do Bailique. Macapá: GEA,1997c. . Projeto Escola Bosque do Amapá: projeto de socialização. Macapá: GEA, 1997d. Hartog, F.Tempo, história e a escrita da história: a ordem do tempo. Revista de História, São Paulo: USP, n. 148, p. 9-34,2003. DOI: https://doi.org/10.11606/issn.2316-9141. v0i148p9-34

Hartog, F. Régimes d'historicité: présentisme et expériences du temps. 2. ed. Lonrai: Éditions du Seuil, 2012.

Harvey, D. Condição pós-moderna. 18. ed. São Paulo: Edições Loyola, 2009.

Новsвашм, E. The age of extremes: a history of world, 1914-1991. Nova York: Vintage, 1995. HöLscher, L. Mysteries of historical order: ruptures, simultaneity and relationship of the past, the present and the future. In: Lorenz, C.; Bevernage, B. (Ed.). Breakin up times: negotiating the borhters betweem present, past and future. Bristol: Vandenhoeck \& Ruprecht, 2013. p. 134-151.

Huertas, D. M. Da fachada atlântica à imensidão amazônica: fronteira agrícola e integração territorial. São Paulo: Annablume, 2009.

JАсові, P. Educação ambiental, cidadania e sustentabilidade. Cadernos de Pesquisa, São Paulo, Fundação Carlos Chagas, n. 118, p. 189-205, mar. 2003. DOI: http://dx.doi. org/10.1590/S0100-15742003000100008

Koselleck, R. Futuro passado: contribuição à semântica dos tempos históricos. Rio de Janeiro: Contraponto, 2006. 
Lima, G. F. C. Educação ambiental crítica: socioambientalismo às sociedades sustentáveis. Educação e Pesquisa, São Paulo: USP, v. 35, n. 1, p. 145-163, jan./abr. 2009. DOI: http://dx.doi.org/10.1590/S1517-9702200900010001

Loвato, S. O futuro da Amazônia: horizonte de expectativa de Arthur Reis (década de 1950). Confins, Paris ; São Paulo: Université Paris 3, Universidade de São Paulo, n. 28, p. 1-15, 2016.

Lyotard, J.-F. A condição pós-moderna. 16. ed. Rio de Janeiro: José Olympio, 2015.

Moulin, N. (Org.). Amapá: um norte para o Brasil. Diálogos com o governador João Alberto Capiberibe. 2. ed. São Paulo: Cortez, 2000.

Nagle, J. A educação na Primeira República. In: Fausto, B. (Dir.). História geral da civilização brasileira. 7. ed. Rio de Janeiro: Bertrand Brasil, 2004. (O Brasil Republicano, t. 3, v. 2)

Nunes, J. G. O caminho da redenção. Amapá, Macapá, n. 52, p. 1, 16 mar. 1943. . Educação. Amapá, Macapá, n. 109, p. 1, 19 abr. 1947. . A verdade sôbre o manganês do Amapá. [Macapá]: 1959. Mimeografado.

O professor rural. Amapá, Macapá, n. 377, p. 5, 7 jun. 1952.

Oito anos DE batalha territorial. Amapá, Macapá, 25 jan. 1952. Editorial, n. 358, p. $1,1^{\text {a }}$ secção.

Pacheco, D. M. S. Narrar o trauma: memórias do naufrágio do barco Novo Amapá. 2016. 64f. Monografia (Especialização em História e Historiografia da Amazônia) Universidade Federal do Amapá, Macapá, 2016.

Pomian, K. La crise de l'avenir. Le Debat, Paris: Éditions Gallimard, n. 7, p. 5-17, 1980. Ratier, R. A Escola Bosque do Amapá poderia ter mudado a educação. Nova Escola, São Paulo: Fundação Nova Escola, n. 281, 1 abr. 2015.

Ribeiro, G. L. Ambientalismo e desenvolvimento sustentado. Nova ideologia/ utopia do desenvolvimento. Revista de Antropologia, São Paulo: USP, n. 34, p. 59-101, 1991. DOI: https://doi.org/10.11606/2179-0892.ra.1991.111253

. Ambientalismo e desenvolvimento sustentado: ideologia e utopia no final do século XX. Ciência da Informação, Brasília: IBCT, v. 1, n. 21, p. 23-31, jan./abr. 1992.

Ricoeur, P. A memória, a história e o esquecimento. Campinas: Editora UNICAMP, 2007. Romanelli, O.O. História da educação no Brasil (1930-1973).30.ed. Petrópolis:Vozes, 2006. SAchs, I. Ecodesenvolvimento: crescer sem destruir. São Paulo: Vértice, 1986.

Saviani, D. Política educacional brasileira: limites e perspectivas. Revista de Educação, Campinas: PUC-Campinas, n. 24, p. 7-16, jun. 2008.

Sorrentino, M.;Trajber, R.; Mendonça, P.; Ferraro Júnior,L.A. Educação ambiental como política pública. Educação e Pesquisa, São Paulo: USP, v. 31, n. 2, p. 285-299, maio/ ago. 2005. DOI: https://doi.org/10.1590/S1517-97022005000200010

Souza, C. A. A. "Varadouros da liberdade": empates no modo de vida dos seringueiros de Brasiléia. 1996. 303f. Tese (Doutorado em História) — Pontifícia Universidade Católica de São Paulo, São Paulo, Acre, 1996. 
Tota, A. P. Cultura, política e modernidade em Noel Rosa. São Paulo em Perspectiva, São Paulo: Fundação SEADE, v. 15, n. 3, p. 45-49, jul./set. 2001. DOI: http://dx.doi. org/10.1590/S0102-88392001000300007

VAsconcellos, G.; Suzuki Júnior, M. A malandragem e a formação da música popular brasileira. In: Fausto, B. (Dir.). História geral da civilização brasileira. São Paulo: DIFEL, 1984. p. 501-523. (O Brasil Republicano, t. 3, v. 4)

Viana, M. O ensino rural como fator de recuperação do nosso caboclo.Amapá, Macapá, n. 138, 1 nov. 1947, n. 138, p. 3. Palestra proferida no recinto da 1a Exposição de Animais do Território.

\section{SOBRE O AUTOR}

Sidney Lobato é doutor em história social pela Universidade de São Paulo (USP). Professor da Universidade Federal do Amapá (UNIFAP). E-mail: lobato.sidney@yahoo.com.br 